\title{
A review of 50 cases of bath-related headache: clinical features and possible diagnostic criteria
}

\author{
Uma revisão de 50 casos de cefaleia relacionada ao banho: características clínicas e \\ possíveis critérios diagnósticos
}

Raimundo Pereira Silva-Néto'

\begin{abstract}
Objective: To describe clinical features and possible diagnostic criteria of the 50 bath-related headache (BRH) cases that have been published in the literature to date. Methods: Based on a literature search in the major medical databases, we analyzed all case reports or case series on BRH that were published between 2000 and 2017. Results: We describe 48 women and two men diagnosed with BRH. Of these 50 patients, $90 \%$ were from Asian countries. The average age was 49.3 years. There was an association of BRH with migraine (28\%), tension-type headache (12\%) and cold stimulus headache (4\%). Headache was bilaterally localized, had an explosive or pulsating quality and a severe intensity. The pain lasted from five minutes to four days. Associated manifestations were nausea, vomiting, photophobia or phonophobia. There was a good therapeutic response with nimodipine and when avoiding a hot bath. Conclusions: Bath-related headache is a benign headache that is not associated with a structural lesion.
\end{abstract}

Keywords: headache disorders; diagnosis, drug therapy

RESUMO

Objetivo: Descrever as características clínicas e possíveis critérios diagnósticos dos 50 casos de cefaleia relacionada ao banho (CRB) que foram publicados na literatura até agora. Métodos: Com base em uma pesquisa de literatura nas principais bases de dados médicos, analisamos todos os relatos de casos ou séries de casos sobre BRH que foram publicados entre 2000 e 2017. Resultados: Descrevemos 48 mulheres e 2 homens diagnosticados com CRB. Destes 50 pacientes, 90,0\% eram asiáticos. A média de idade foi 49,3 anos. Houve associação com migrânea (28,0\%), cefaleia do tipo tensional (12,0\%) e cefaleia por estímulo frio (4,0\%). A cefaleia foi localizada bilateralmente, explosiva ou pulsátil e de forte intensidade. A dor durou de 5 minutos a 4 dias. As manifestações associadas foram náuseas, vômitos, fotofobia ou fonofobia. Houve uma boa resposta terapêutica com nimodipina e evitando-se banho quente. Conclusões: CRB é uma cefaleia benigna não associada com lesão estrutural.

Palavras-chave: transtornos da cefaleia, diagnóstico, tratamento farmacológico

Bath-related headache $(\mathrm{BRH})$ is a rare headache disorder first described by Negoro et al. in 2000 with the name of "benign hot bath-related headache"1. In 2003, after publication of four more cases, the authors suggested the term "bathing headache"

This headache disorder is characterized by its development while the patient is bathing in hot water or being immersed in a hot bath. There is not yet a diagnostic criterion for BRH and it has not been described in the International Classification of Headache Disorders, Third Edition (beta version) ${ }^{3}$.
To date, only a few BRH cases have been described in the literature, most of which are case reports ${ }^{1,2,4,5,6,7,8,9,10,11,12,13,14}$. There is only one large series published with 21 cases $^{15}$. Therefore, it is still not well characterized clinically. As a consequence of the rarity of $\mathrm{BRH}$, the pathophysiology remains unclear ${ }^{16}$.

We present the first review on all cases of BRH that have been published since the initial description, and highlight their main clinical characteristics.

'Universidade Federal do Piauí, Disciplina de Neurologia, Teresina PI, Brasil.

Correspondence: Raimundo Pereira Silva-Néto; UFPI;Avenida Frei Serafim, 2280; 64001-020 Teresina PI; Brasil; E-mail: neurocefaleia@terra.com.br Conflict of interest: There is no conflict to declare.

Received 23 November 2017; Received in final form 20 January 2018; Accepted 13 February 2018. 


\section{METHODS}

Based on a literature search in the major medical databases (LiLacs, SciELO, Bireme, Scopus, EBSCO and PubMed), we analyzed all case reports or case series on $\mathrm{BRH}$ that were published in the period between 2000 (the first description) and 2017.

All reported patients were included regardless of which diagnostic criteria had been adopted. Because there are no diagnostic criteria for BRH established by the International Classification of Headache Disorders ${ }^{3}$, we enrolled all cases where the patients were defined by the authors as having BRH.

Data were analyzed based on demographic and clinical features, therapeutic experience and clinical outcomes. Data are presented as an arithmetic mean with the standard deviation (SD), or as percentages. The percentage is always related to the total number of patients whose information was available for the specific issue.

All collected data were organized in a database. The BioEstat version 5.0 for statistical analysis was used.

\section{RESULTS}

A total of 50 patients were diagnosed with $\mathrm{BRH}$ in this review. We describe the various clinical features, the therapeutic options and outcome in these patients. The clinical features of all patients with $\mathrm{BRH}$ are summarized in Table 1.

Regarding the geographical and ethnic distribution of $\mathrm{BRH}$, we found that $45(90 \%)$ patients were from Asian countries. A total of 26 (52\%) patients were found in Taiwan. The remaining 24 patients were found in the following countries: China (6), Japan (5), Turkey (4), India (3), South Korea (1), Spain (1), France (an African patient), and Brazil (3).

Of the 50 patients with BRH, 48 (96\%) were women and two (4\%) men. Considering only the 29 case reports, the average age of the patients was $45.9 \pm 12.9$ years, ranging from 18 to 67 years, but in the series of 21 patients $^{15}$, the average age was $54 \pm 8$ years old and ranged from 32 to 76 years. From these data, we found that the average age of all patients with $\mathrm{BRH}$ was 49.3 years and ranged from 18 to 76 years.

There was no patient with a family history of BRH, but there was an association with other primary headaches in the following order of frequency: migraine (28\%), tensiontype headache (12\%) and cold stimulus headache (4\%).

Most patients had three or more episodes of $\mathrm{BRH}$ and these occurred most often during a hot bath (Table 2). In more than $50 \%$ of the patients, headache was bilaterally localized, with an explosive or pulsatile character. All patients reported that the intensity of pain was severe. The duration of pain ranged from five minutes to four days, with an average of 60-180 minutes.
The most frequent manifestations associated with BRH were nausea, vomiting, photophobia or phonophobia. Associated symptoms were absent or not reported in $34 \%$ of the patients. There was no description of autonomic manifestation in any patient.

Both medical and neurological examinations were normal in all patients. Almost all the patients (96\%) with BRH underwent the following imaging studies: computed tomography, magnetic resonance imaging, magnetic resonance angiography, computed tomography angiography and/or transcranial Doppler. In $34.7 \%$ of these patients, the examinations showed focal narrowing of cerebral arteries (Table 3).

A pharmacological or non pharmacological treatment was used by the majority of the patients. The most commonly used drugs were nimodipine (48\%) and migraine prophylactics (10\%), which had a good therapeutic response. However, the most improved therapeutic response occurred in patients who avoided a hot bath $(8 / 50 ; 16 \%)$.

\section{DISCUSSION}

In 1988, a headache attributed to the external application of a cold stimulus was recognized by the International Headache Society ${ }^{17}$. This headache occurs when a cold stimulus is applied externally to the head, such as immersion of the head in ice water ${ }^{3}$.

In recent years, descriptions of a new headache have appeared, in which a warm stimulus applied to the head provoked the headache. The onset of this headache may occur during a cold bath ${ }^{11}$. However, in almost all patients, the headache started during a hot bath, especially when pouring hot water over her- or himself $1,2,5,7,8,9,10,12,13,14,15$, but this headache also occurred when the patient was getting out of the hot bath ${ }^{4}$ or washing his/her hair ${ }^{6}$.

Since the first description of $\mathrm{BRH}^{1}$, the frequency of diagnoses has gradually increased in recent years. This fact is possibly due to the increasing recognition of this headache disorder. The exact prevalence of $\mathrm{BRH}$ is unknown and needs further investigation. It cannot be calculated based on the literature. However, in the only series of patients that has been published, the authors found a prevalence of $0.4 \%{ }^{15}$.

The first description of BRH was made only in women in their fifth decade of life ${ }^{1}$. A few years later, the large case series by Wang et al., also found this headache only in women after age $50^{15}$. When we analyzed all the patients described in the literature, we found that BRH occurs almost exclusively in middle-aged women.

According to the geographical location of the 50 cases described, we identified only five non-Asian patients (one Spanish, one African and three Brazilian) $)^{7,10,13,14}$. From this finding, we speculate whether the occurrence of $\mathrm{BRH}$ depends on Asian ancestry. 


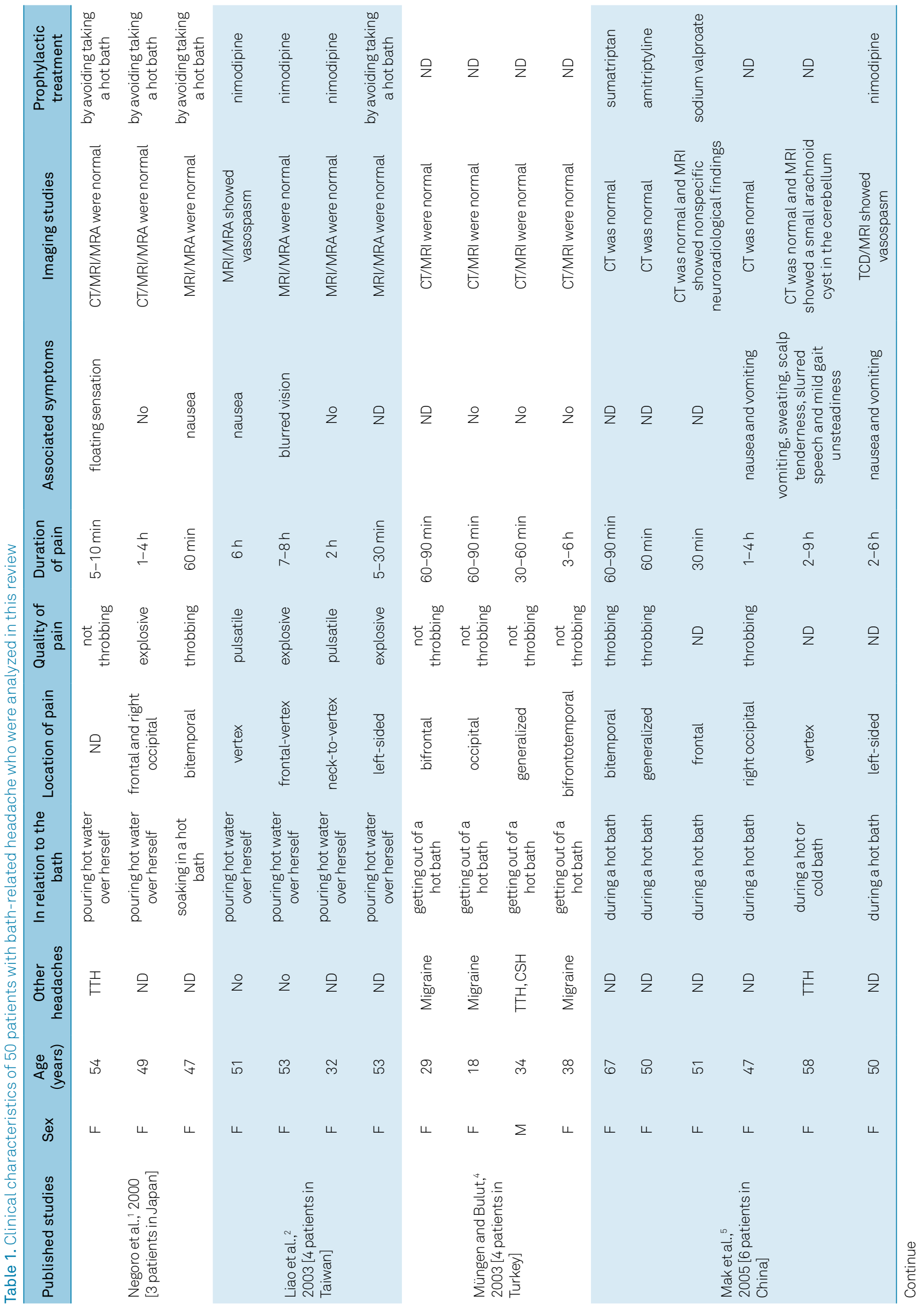




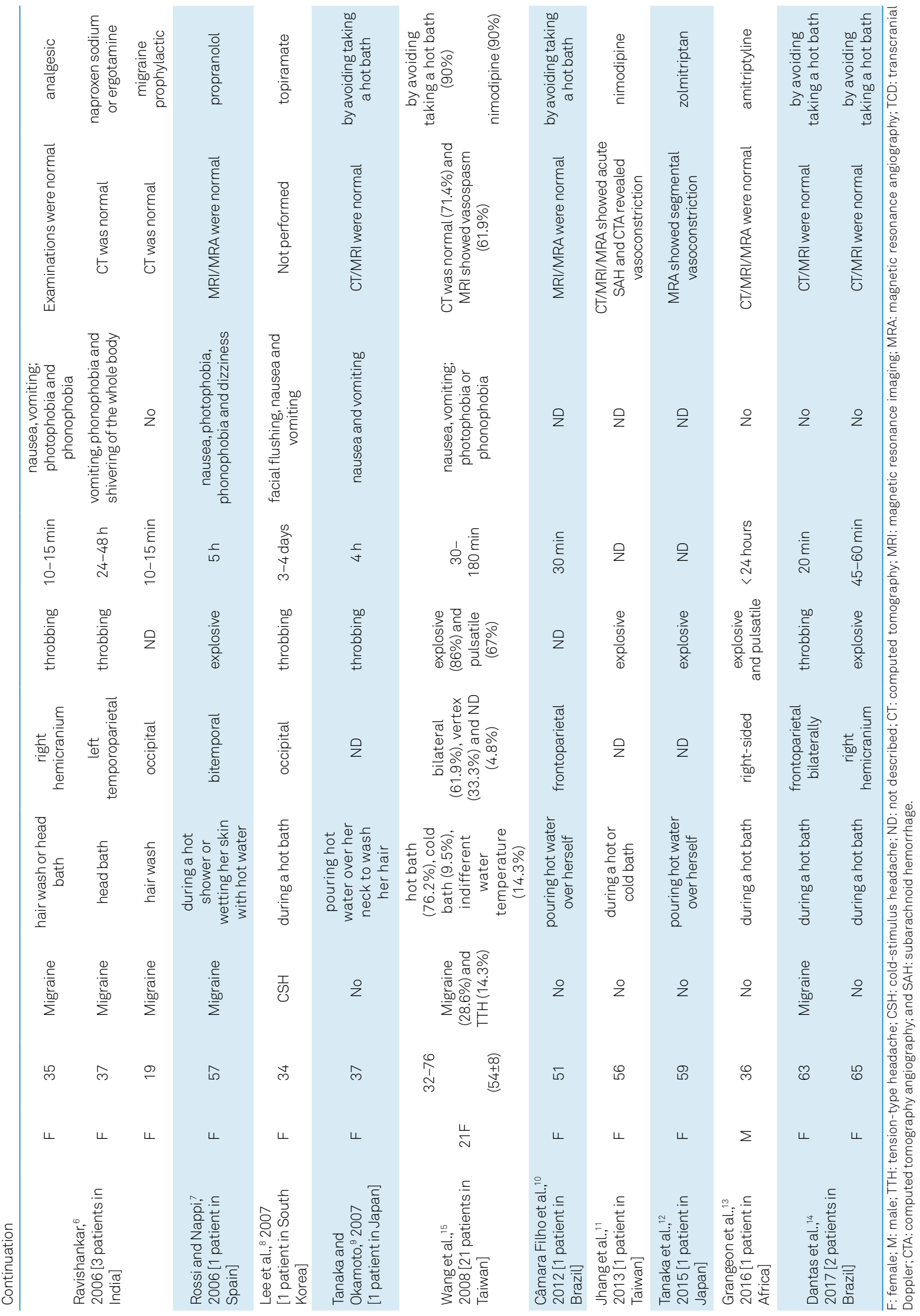


Despite the association of BRH with other primary headaches, especially migraine $e^{4,6,7,14,15}$ and tension-type headache ${ }^{1,4,5,15}$, the diagnosis of this headache disorder should only be made when other headaches have been excluded. In the studies in this review, neuroradiological examinations showed vasospasm in $34.7 \%$ of the patients.

The pathophysiological mechanism of $\mathrm{BRH}$ is unknown ${ }^{16}$, but it is assumed that in predisposed individuals, excessive stimulation of the scalp's temperature-sensitive receptors may cause this headache ${ }^{18}$. The bath may be one of the triggers of the reversible cerebral vasoconstriction syndrome and prophylactic use of nimodipine may shorten the duration of attacks ${ }^{2}$.

Bath-related headache may be considered a primary headache when there is no cerebral arterial vasospasm or identifiable pathology, similar to primary thunderclap headache. If there is evidence of intracranial vasoconstriction, it would be considered as headache attributed to reversible cerebral vasoconstriction syndrome ${ }^{3}$.

Based on the absence or presence of vasoconstriction demonstrated by magnetic resonance angiography, approximately $65 \%$ of the patients fulfilled the criteria for a diagnosis of primary headache and the remaining $35 \%$ could be classified as reversible cerebral vasoconstriction syndrome ${ }^{3}$. Nimodipine was effective in preventing headache attacks secondary to vasospasm in $80 \%$ of the patients ${ }^{19}$.

From the initial description of the BRH, all patients were taking a warm bath ${ }^{1}$ and the pain disappeared spontaneously after a period of two to three weeks. Most of these patients did not present with alterations in the imaging examinations. Therefore, we believe that $\mathrm{BRH}$ is a primary headache and we suggest possible diagnostic criteria for it (Table 4).

In this review, successful acute and prophylactic treatments of $\mathrm{BRH}$ included, primarily, the avoidance of hot baths. However, these treatment recommendations are based on case reports and need further validation. In most cases, the pain is self limited in the period of a week to a few months. To date, there is no effective prophylactic treatment,
Table 2. Temperature of the water that triggered the bathrelated headache in 50 patients.

\begin{tabular}{lcc}
\hline \multirow{2}{*}{ Water temperature } & \multicolumn{2}{c}{ Patients } \\
\cline { 2 - 3 } & $\mathrm{N}$ & $\%$ \\
\hline Hot water & 41 & 82 \\
Cold water & 2 & 4 \\
Not indicated & 7 & 14 \\
\hline
\end{tabular}

Table 3. Neuroradiological findings in 49 patients with bathrelated headache submitted to imaging studies.

\begin{tabular}{lcc}
\hline \multirow{2}{*}{ Neuroradiological findings } & \multicolumn{3}{c}{ Patients } \\
\cline { 2 - 3 } No abnormalities & $\mathrm{n}$ & $\%$ \\
Vasospasm & 30 & 61.2 \\
Nonspecific changes & 17 & 34.7 \\
\hline
\end{tabular}

Table 4. Suggested diagnostic criteria for bath-related headache.

\section{Suggested diagnostic criteria}

A. At least two acute headache episodes fulfilling criteria B-D

\section{B. The patient is taking a hot bath}

C. Evidence of causation demonstrated by both of the following: headache developed during a hot bath, headache did not recur after avoiding hot baths

D. Headache has at least two of the following four characteristics: bilateral location, moderate or severe pain intensity, explosive or pulsating quality, lasting 60-180 minutes

E. Not better accounted for by another International Classification of Headache Disorders diagnosis

although some drugs have been used, among them topiramate $^{20}$, amitriptyline $e^{5,13}$, sodium valproate ${ }^{5}$, propranolol ${ }^{7}$ and varenicline $^{21}$. Avoiding a hot bath prevents the onset of pain and seems to be the most effective treatment.

In conclusion, BRH is a benign headache not associated with a structural lesion.

\section{References}

1. Negoro K, Morimatsu M, Ikuta N, Nogaki H. Benign hot bath-related headache. Headache. 2000 Feb;40(2):173-5. https://doi.org/10.1046/j.1526-4610.2000.00026.x

2. Liao YC, Fuh JL, Lirng JF, Lu SR, Wu ZA, Wang SJ. Bathing headache: a variant of idiopathic thunderclap headache. Cephalalgia. 2003 Nov;23(9):854-9. https://doi.org/10.1046/j.1468-2982.2003.00603.x

3. Headache Classification Subcommittee of the International Headache Society. The International Classification of Headache Disorders, 3rd edition (beta version). Cephalalgia. 2013 Jun;33(9):629-808. https://doi.org/10.1177/0333102413485658

4. Müngen B, Bulut S. Hot bath-related headache: four cases with headaches occurring after taking a hot bath. Cephalalgia. 2003 Oct;23(8):846-9. https://doi.org/10.1046/j.1468-2982.2003.00562.x
5. Mak W, Tsang KL, Tsoi TH, Au Yeung KM, Chan KH, Cheng TS et al. Bath-related headache. Cephalalgia. 2005 Mar;25(3):191-8. https://doi.org/10.1111/j.1468-2982.2004.00832.x

6. Ravishankar K. 'Hair wash' or 'head bath' triggering migraine - observations in 94 Indian patients. Cephalalgia. 2006 Nov;26(11):1330-4. https://doi.org/10.1111/j.1468-2982.2006.01223.x

7. Rossi P, Nappi G. Bath-related headache: the first European case. Cephalalgia. 2006 Dec;26(12):1485-6. https://doi.org/10.1111/j.1468-2982.2006.01204.x

8. Lee J, Yun $\mathrm{CH}$, Chu MK, Ha CK. Hot bath-related headache controlled by topiramate. Cephalalgia. 2007 May;27(5):465-7. https://doi.org/10.1111/j.1468-2982.2007.01308.x

9. Tanaka M, Okamoto K. Bath-related headache: a case report. Cephalalgia. 2007 Jun;27(6):563-5. https://doi.org/10.1111/j.1468-2982.2007.01322.x 
10. Câmara Filho JW, Medeiros FL, Sougey EB. Bath-related headache: a Brazilian case report. Arq Neuropsiquiatr. 2012 May;70(5):383-4. https://doi.org/10.1590/S0004-282X2012000500015

11. Jhang KM, Lin CH, Lee KW, Chen YY. Bath-related thunderclap headache associated with subarachnoid and intracerebral hemorrhage. Acta Neurol Taiwan. 2013 Sep;22(3):127-32.

12. Tanaka R, Ando M, Shimura H, Yamashiro K, Hattori N. Bathrelated headache controlled by zolmitriptan. Neurol Clin Neurosci. 2015;3(5):200-2. https://doi.org/10.1111/ncn3.12008.

13. Grangeon L, Ozel G, Guégan-Massardier E, Lefaucheur R. Bath-related thunderclap headache: case report of a male patient. Headache. 2016 Nov;56(10):1664-6. https://doi.org/10.1111/head.12900

14. Dantas JH, Gomes JL, Pereira ML, Moreira FC, Coelho RF, Silva-Neto RP. Bath-related headache: two cases report in Brazil. Int J Case Rep Short Rev. 2017;3(3):57-9.

15. Wang SJ, Fuh JL, Wu ZA, Chen SP, Lirng JF. Bath-related thunderclap headache: a study of
21 consecutive patients. Cephalalgia. 2008 May;28(5):524-30. https://doi.org/10.1111/j.1468-2982.2008.01541.x

16. Ravishankar K. 'Hair-wash headache'-an unusual trigger for migraine in Indian patients. Cephalalgia. 2005 Dec;25(12):1184-5 https://doi.org/10.1111/j.1468-2982.2005.01003.x

17. Headache Classification Subcommittee of the International Headache Society. The International Classification of Headache Disorders, 1 nd edition. Cephalalgia. 1988;8(Suppl 7):10-96.

18. Maranhão-Filho P, Vincent MB. [Uncommon headaches: from Zeus to Harry Potter]. Rev Bras Neurol. 2010 jul-set;46(3):5-13. Portuguese.

19. Solomon S, Dodick DW. Bathing headache: a variant of idiopathic thunderclap headache [Editorial]. Cephalalgia. 2003 Nov;23(9):853. https://doi.org/10.1046/j.1468-2982.2003.00607.x

20. Ravishankar K. Bath-related headache and topiramate. Cephalalgia. 2008 Jan;28(1):97-8.

21. Valença MM. Bath-related headache induced by varenicline. Arq Neuropsiquiatr. 2012 Nov;70(11):908. https://doi.org/10.1590/S0004-282X2012001100020 